\title{
Helala Duyarlı Turistlerde Sürdürülebilir Turizm Gelişmesine Yönelik Alg1 Araştırması
}

\author{
Hüseyin PAMUKÇU ${ }^{1}$, Ömer SARAÇ² ve Orhan BATMAN ${ }^{3}$
}

$\ddot{O} z$

İslamiyet; çevreyi korumayı emreden, israfı yasaklayan ve toplumların sosyal yaşantısı ve inancına sayg1 duyan semavi bir dindir. İslam dininin gereklerine göre turizm faaliyeti gerçekleştiren bireylerin sürdürülebilir turizme katkı sağladığı düşünülmektedir. Bu doğrultuda bu araştırmanın temel amacı, İslam dinine mensup helala duyarlı turistlerin sürdürülebilir turizm gelişimine yönelik algilarının ortaya konulmasıdır. Veriler beş yıldızlı helal konseptli otellerde konaklayan toplamda 486 kişiden anket tekniği ile toplanmıştır. Araştırma sonuçları helala duyarlı turistlerin turizm faaliyeti gösterdikleri destinasyonun sürdürülebilirliğine duyarlı olduklarını ve İslam dinin gerekleri arasında sayılan çevrenin korunması ve israftan kaçllması emirlerini benimsediklerini göstermektedir. Helala duyarlı turistlerin sürdürülebilir turizmin gelişiminde öncelikle çevresel konulara dikkat ettiği ve sürdürülebilir turizm gelişiminde uzun vadeli planlamaların yapılması gerektiği düşüncesinde oldukları tespit edilmiştir.

Anahtar Kelimeler: Turizm, Helal turizm, Sürdürülebilirlik, Turist algis1

\section{Halal-Sensitive Tourist Perceptions for Sustainable Tourism Development}

\begin{abstract}
Islam; It is a celestial religion that orders to protect the environment, prohibits waste and respects the social life and beliefs of societies. It is thought that individuals who carry out tourism activities according to the requirements of the Islamic religion contribute to sustainable tourism. Accordingly, the main purpose of this research is to reveal the perceptions of halal-sensitive tourists belonging to the Islamic religion towards sustainable tourism development. The data were collected from a total of 486 people who stayed in five-star halal-concept hotels with a survey technique. The results of the research show that halal-sensitive tourists are sensitive to the sustainability of the destination where they do touristic activities, and that they adopt the orders "protecting the environment and avoiding waste" which are considered among the requirements of Islam. It has been determined that halal-sensitive tourists think that firstly environmental issues should be paid attention and long-term planning should be made in sustainable tourism development.
\end{abstract}

Key Words: Tourism, Halal tourism, Sustainability, Tourist perception

\section{Atıf İçin / Please Cite As:}

Pamukçu, H., Saraç, Ö. ve Batman, O. (2020). Helala duyarlı turistlerde sürdürülebilir turizm gelişmesine yönelik alg1 araştırmasi. Manas Sosyal Araştırmalar Dergisi, 9(4), 2600-2610.

Geliş Tarihi / Received Date: 27.05.2020

Kabul Tarihi / Accepted Date: 21.07.2020

\footnotetext{
${ }^{1}$ Dr. Öğr. Üyesi. - Kastamonu Üniversitesi Turizm Fakültesi, pamukcuhuseyin@gmail.com ORCID: 0000-0002-9673-5604

2 Öğr. Gör. - Kastamonu Üniversitesi Cide Rifat Ilgaz Meslek Yüksekokulu, o.sarac@kastamonu.edu.tr ORCID: 0000-0002-4338-7394

3 Prof. Dr - Sakarya Uygulamalı Bilimler Üniversitesi Turizm Fakültesi, obatman@subu.edu.tr ORCID: 0000-0001-7186-7064
} 


\section{Giriş}

Turizm, çok eskilere dayanan bir seyahat faaliyetidir. Bu faaliyetler ilk zamanlarda din, sağllk ve ticaret amacıyla gerçekleştirilmekteydi. İlerleyen dönemlerde kültür amaçlı geziler de yapılmaya başladı. Kültür amaçlı geziler yapılan bu dönemlerde ise turizm, ruhani lider ve aristokrat sınıfı çevrelerinin gerçekleştirebildiği oldukça lüks bir aktivite durumundaydi. Lüks olması faaliyetlerin asgari düzeyde seyretmesine neden olmaktadır. Bu nedenle bu dönemlerde turizmin çevre üzerinde fiziksel, sosyal ya da kültürel baskısı tedbir gerektiren bir boyuta ulaşmamıştır. Ancak sanayi devrimi ve özellikle II. Dünya Savaşından sonra ekonomik kazancın artması, eğitim seviyesinin yükselmesiyle merak duygusunun ortaya çıkması ve teknolojik gelişmeler sonucu mesafelerin kısalıp güvenli bir ortamın oluşması bireylerin boş zamanlarını turizm faaliyetleriyle doldurmasına vesile olmuştur (Weaver ve Oppermann, 2000, s. 69).

Sanayi devriminden sonra iş hayatında yaşanan farklılıklar; insanların tatil yapma, dinlenme ve eğlenme gibi ihtiyaçlarının artış göstermesine ve bu ihtiyaçların deniz-güneş-kum üçlüsü ile karşılanmasına neden olmuştur. Yaşanan teknolojik ve ekonomik gelişmeler ise turizm faaliyetlerinin kitleler halinde gerçekleşmesinin önünü açmıştır. Kitlesel turizm faaliyetleri, varış yerinin ekonomik kazanç elde etmesine fayda sağlarken etkin bir turizm planlamasının olmadığ yerlerde çevresel ve sosyo-kültürel sorunların ortaya çıkmasına neden olmaktadır (Koçoğlu, vd., 2020, s. 206). Bunun en önemli nedeni destinasyonun taşıma kapasitesinin üzerinde hizmet vermesidir. Sosyal yapının ya da çevrenin kendisini yenilemesine müsaade edilmeksizin gerçekleştirilen aşırı kullanım; bu yörelerdeki doğal güzellikleri, kültürel yapıyı, ekolojik dengeyi ve biyolojik çeşitliliğin bozulmasına neden olmaktadır (Kahraman ve Türkay, 2018). Bunun önüne geçebilmek destinasyonların sürdürülebilir turizm gelişimine destek vermekle mümkün olmaktadir.

Sürdürülebilir turizm gelişiminin sağlanması için turizm çekiciliklerini oluşturan doğal, tarihi ve sosyokültürel değerlerin gelecek nesillere ulaşabilecek şekilde korunması, geliştirilmesi ve kalitesinin arttır1ması gerekmektedir (Saraç ve Tanrısever, 2018). Bu bağlamda turizmin sürdürülebilirliğinde; ekonomik, sosyal, kültürel ve çevresel boyutların birlikte değerlendirilmesi gerekmektedir (Dolnicar, Crouch ve Long, 2008). Özellikle 1950'li ylllardan sonra büyük bir gelişme gösteren kitlesel turizm, belirli dönem ve yerlerde yoğunlaşmış olmasının bir gereği olarak sosyal, kültürel ve çevresel yapıda birtakım olumsuzlukların oluşmasına neden olmaktadır (Kozak ve Martin, 2012). Çünkü turizm işletme ya da destinasyonlanı ekonomik gelir elde etmeye yönelik faaliyetler sergilerken bulundukları bölgenin sosyo-kültürel ve çevresel sorunlarını göz ardı etmektedir.

Buna karşın son zamanlarda helal turizm yaklaşımının sürdürülebilir turizm gelişiminin sağlanmasında önem taşıdığı düşünülmektedir. Bu turizm yaklaşımı İslam dinine mensup mütedeyyin turistlerin turizm faaliyetlerinde bulunurken, dini görev ve vecibelerini de yerine getirmesine olanak sağlamaktadır. Bu turizm yaklaşımının, sürdürülebilirlikle ilişkili diğer yaklaşımlardan en büyük farkı, çoğunlukla İslam dinine ait düşünce ve itikatları olan mütedeyyin turistler tarafından gerçekleştiriliyor olmasıdır. Bu yönüyle helal turizm, kitle turizminin aksine çevreci, israfı yasaklayan, insan sağlı̆̆ına ve sosyal yaşantısına değer veren yapısıyla ön plana çıkmaktadır (Sarı, 2017, s. 507). Bunun yanı sıra helal turizmin büyük bir yükselişe ve potansiyele sahip olması sürdürülebilir turizm gelişimine katkı sağlayıp sağlayamayacağının sorgulanmasını zaruri kilmaktadır.

Helal turizm, İslam dinine mensup helala duyarlllı̆̆ı yüksek turistlere inançları doğrultusunda hizmet vermeye çalışan bir yaklaşımdır. Bu kapsamda helala duyarlı turistlerin seyahatlerinde dinlerini yaşamalarına yardımcı olan helal konseptli oteller faaliyet göstermektedir. Afyonkarahisar, helal konseptli otellerin kümelenme gösterdiği illerden biridir. Bu destinasyonu ziyaret eden, helal konseptli otellerde kalan ve turizm faaliyetlerini inançları doğrultusunda sürdüren helala duyarlı turistlerin, tutum ve davranışlarının sürdürülebilir turizmin gereklerine ne kadar paralel bir yapıya sahip olduğunun belirlenmesi hem literatürü genişletmesi hem de uygulama alanında arz belirleyicilere yön vermesi bakımından önem taşımaktadır.

$\mathrm{Bu}$ araştırmanın temel amac1, sürdürülebilir turizm gelişimine yönelik helala duyarlı turistlerin algılarını belirlemektir. Sürdürülebilir turizm gelişimine yönelik boyutlar arasındaki ilişkilerin tespit edilmesi çalısmanın diğer amaçları arasında yer almaktadır. Bu kapsamda sürdürülebilir turizm ve helal turizmin literatür özeti verildikten sonra yöntem ve saha araştırmasından elde edilen bulgular tartışılacaktır. 


\section{Sürdürülebilir Turizm}

Sürdürülebilirlik en basit anlamıyla bugünün ihtiyaçlanı karşılanırken gelecek neslin ihtiyaçlarının da karşılanmasına olanak veren bir çevrenin bırakılmasıdır (Collin, 2004). Sanayi devriminden sonra kaynaklar sorumsuzca tüketilmiş, üretim artmış ve üretilen ürünlerin özendirilerek satışı sağlanmıştır. Bu durum zaman içerisinde ekonomik geliri arttırabilmek için daha fazla üretim yapılmasını gerektiren bir dönemin başlamasına neden olmuştur. Bu dönemde sürdürülebilirliğin ekonomik boyutuna önem verilirken çevresel boyut arka planda bırakılmıştır. Bir başka ifadeyle doğadaki kıt kaynaklar doğanın kendisini yenilemesine müsaade edilmeksizin tüketilmekte doğa ise varllğını sürdürmekte her geçen gün güçlük çekmektedir.

Sürdürülebilirliğin sağlanması için çevrenin azami ölçüde korunması gerekmektedir. Bir destinasyona ait çevre korunduğunda üretim yapılamayacağı algısı hâkimdir. Ancak durum öyle değildir. $\mathrm{Bu}$ kaynaklardan kendisini yenilemesine müsaade edecek şekilde istifade edilmesi gelecek neslin de bu kaynaklardan yararlanmasina izin verilmesi anlamina gelmektedir. Bu durum ekolojik dengenin de korunmasını sağlayacak ve yaşamın kalitesi artacaktır (Kahraman ve Türkay, 2015).

Turizmin çevreyle olan ilişkisi daha çok 1960 'lı yıllardan sonra ortaya çıkmıştır. Turizm çevre ilişkisini ele alan ilk bildiri 1980'de yapılan Manila bildirgesidir (Kahraman ve Türkay, 2015, s. 44). Bu bildirgeye göre turizm için çevre önemli ve gereklidir. Bu nedenle gelecek nesillere de ulaştırılabilmesi için korunması gerekmektedir. Buna karşın turizm yapısı itibariyle hem doğal hem sosyal çevreye aşırı kullanımla alakalı olarak baskı yapmakta; ancak turizm işletmeleri bu baskının gereği olarak ortaya çıkan ek maliyetleri karşılamak istememektedir. Bu durum o bölgeye ait hem fiziksel hem toplumsal çevrenin yok olmasina neden olmaktadır. Turizmin her geçen gün gelişmeye devam etmesi ve gelişmekte olan ülkelere doğru kaymasi; bu gelişmekte olan ülkelerin ise ekonomik dar boğazdan kurtulabilmek için turizm faaliyetlerinin sadece ekonomik boyutlarına odaklanıp onlara ek maliyet getiren sosyal ve fiziksel çevrenin varllğını sürdürmeleri için harcama yapmalarına engel teşkil etmektedir. Bu durum biyo çeşitliliğin azalmasına, ekolojik dengenin bozulmasına, küresel 1sınmaya, kültürel değerlerin kaybolmasına, sosyal adalet ve eşitlik kavramlarının yitirilmesine neden olmaktadır (Kahraman ve Türkay, 2015). Bu düşünceden hareketle sürdürülebilir turizm kavramı her geçen gün önem kazanmaktadır.

Sürdürülebilir turizm, bir turizm destinasyonunda yer alan ürünlerin gelecekte kullanılmaya devam etmesini sağlayacak şekilde tüketilmesi olarak tanımlanmaktadır (Swarbrooke, 1999, s. 13). Sürdürülebilir turizm, sürekliliği sağlanmış bir turizm sisteminin varlığının kesintisiz bir şekilde sürdürülmesi için, aşırı kullanım ve sorumsuzca bir tüketimin önüne geçerek taşıma kapasitesinin aşılmamasına duyarlılık göstermektedir (Çakılcığlu, 2013, s. 28; Koçoğlu vd., 2020).

Türkiye'de turizm 1980’li yıllarda büyük bir sıçramaya tanıklık etmiştir. Yabancı sermayenin ülkeye girdiği o yıllarda turizm, devlet sübvansiyonları ile desteklenmiş “Turizm Teşvik Kanunu” ile kitlesel turizmin gelişmesine kapilar aralanmıştır. Türkiye'nin o yllarda ekonomik olarak önemli kazançlar elde etmesine karşın, kitlesel turizmin bir gereği olarak ortaya çıkan aşırı kullanım ve taşıma kapasitesinin aşımı, ülkeyi çevresel ve sosyo-kültürel sorunlarla karşı karşıya bırakmıştır. Bu sorunların ortaya çıkmasında destinasyona ait altyap1 ve üstyap1 yetersizlikleri önemli rol oynamaktadır. Altyap1 ve üst yap1 yetersizliklerin giderilmesine yönelik gerçekleştirilen yatırımlar ise yoğun sezonlarda kitle turizmin ihtiyaçlarına cevap verememekte, bunun bir sonucu olarak da doğal kaynaklar tükenmekte ve turizm destinasyonları çekiciliklerini kaybetmektedir (Deng vd., 2002, s. 423; Lim ve McAleer, 2005, s. 1431; Türkay ve Saraç, 2019, s. 99). Bu duruma en çok Ege ve Akdeniz kıyı bölgelerinde rastlanmaktadır. Türkiye'nin kitlesel turizm lokomotifi olan bu bölgelerde taşıma kapasitesi aşılarak hem çarpık bir kentleşmenin oluşması hem de tarih, kültür ve sosyal yapıda olumsuzlukların meydana gelmesi gibi sorunlar ortaya çıkmaktadır (Şen, 2010, s. 1). Bunun bir gereği olarak özgünlüğünü yitirmiş birbirine benzeyen turizm yapıları ve destinasyonları oluşmaktadır. Bunun yanı sıra sadece ekonomik boyutu ele alınan ve çevresel, sosyo-kültürel boyutları göz ardı edilmiş bölgelerde ikamet eden yerel halk, turizmin gelişmesine engel olmak istemektedir. Çünkü nasıl turizm faaliyetlerinin yaşadığı yere faydalı olduğunu düşünen yerel halk gelişmesine katk1 sağlamak istemekteyse sorun olduğunu düşünenler de turizmin gelişmesine karşs çıkmaktadır (Kim vd., 2013; Abdollahzadeh ve Sharifzadeh, 2014).

Bu nedenle sürdürülebilir turizm gelişiminde Şekil 1'de görüldüğü üzere ekonomik, çevresel ve sosyokültürel boyutun birlikte ele alınabilmesi, yerel halkın tutumlarının olumlu ölçüde bir etki oluşturması ve ziyaretçi memnuniyetinin sağlanması şüphesiz başarılı bir planlama ile gerçekleşmektedir (Koçoğlu, vd., 2020, s. 206). 


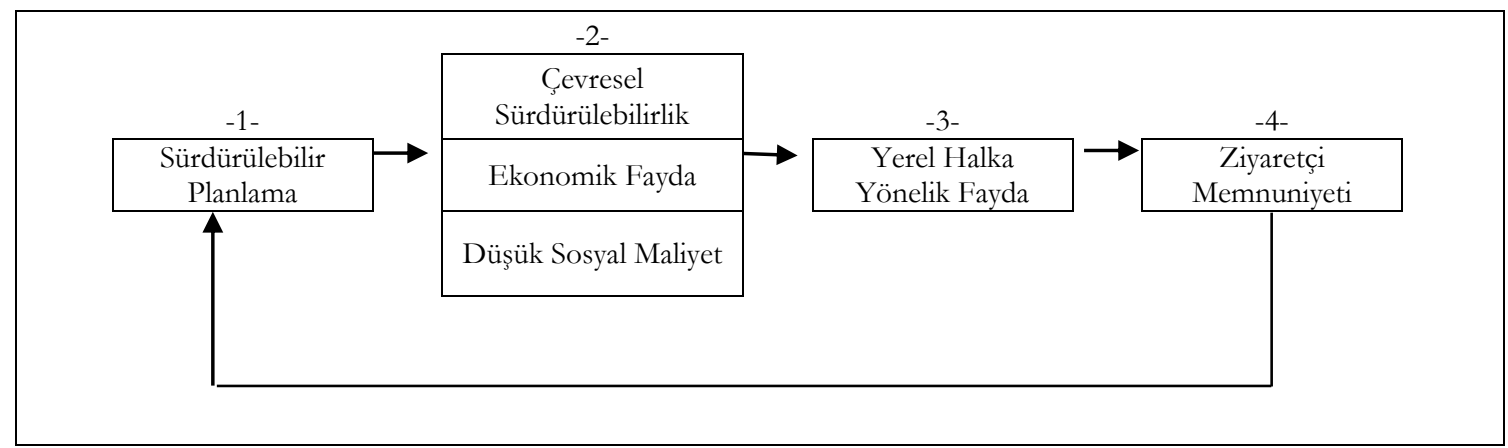

Şekil 1. Sürdürülebilir Turizm Gelişimi (Koģoğlu, vd., 2020, s. 206).

Şekil 1'de gösterildiği üzere sürdürülebilir bir planlanma, çevresel sürdürülebilirliği gerçekleştirmekte, ekonomik fayda sağlamakta ve sosyal maliyetin düşmesine neden olmaktadır. Sosyal maliyet, turizmin bir destinasyonda yaşayan yerel halka fayda sağlamaktan ziyade zarar vermesi anlamına gelmektedir. Böyle bir durumda düşük sosyal maliyet, yerel halka yönelik fayda sağlamakta ve yerel halk turizmin gelişmesine engel olmak yerine katkıda bulunmaktadır. Yerel halkın bu doğrultudaki motivasyonu şüphesiz ziyaretçi memnuniyetinin de artmasını sağlamakta ve sürdürülebilir turizm gelişimi bu durumdan olumlu etkilenmektedir.

Tüm anlatılanlar ışığında sürdürülebilir turizmin gelişebilmesinde en önemli unsurların ekonomik, sosyokültürel ve çevresel boyut olduğu söylenebilmektedir. Bu boyutların birlikte ele alınabilmesi ve planlamanın bu düstur üzerine kurulması destinasyonların sürdürülebilirliğini mutlak başarıya ulaştırmaktadır. İslam dininin israfi yasaklayan, sosyal yaşantıya ve inanca saygı duyan ve çevreyi koruyan bir yapısı vardır. Şayet helal turizm yaklaşımından istifade etmek isteyen İslam dinine mensup mütedeyyin turistler hayatlarını İslam dinin gereklerini yerine getirmek üzere yaşıorsa turizm faaliyetlerinden de aynı ölçüde yararlanmak isteyecektir. Böyle bir durumun sürdürülebilir turizmin gelişmesinde önemli bir yapıtaşı görevi üstleneceği düşünülmektedir. $\mathrm{Bu}$ durumda turizm arzının belirleyicileri turizm pazarlama faaliyetlerini bu minvalde yürütmek zorunda kalmaktadır. Zira turizm arzı turizm talebi doğrultusunda şekillenmektedir.

\section{Helal Turizm}

Helal turizm; İslam dinine mensup mütedeyyin turistlerin gerçekleştirmiş olduğu turizm faaliyetleri doğrultusunda ortaya çıkan ihtiyaçların İslami inanışlar ve kurallar kapsamında karşılanmasına olanak veren bir turizm yaklaşımıdır (Arpacı ve Batman, 2015, s. 186; Tekin, 2016; Pamukçu ve Sarışsk, 2020).

Helal konseptli oteller Türkiye'de 1996 yllından sonra varlık bulmuştur. Bu oteller 2002 yllından sonra "helal turizm" kapsamında değer kazanarak artış göstermeye başlamıştır (Yeşiltaş, Cankül ve Temizkan, 2012, s. 196; Büyükşalvarc1 vd., 2016, s. 1058; Tekin, 2014; Tekin ve Y1lmaz, 2016). Turizm faaliyetlerinin sanayi devrimi ile başlayıp II. Dünya Savaşı sonrasında özellikle 1950-1970 yıllarında gelişme gösterdiği düşünüldügünde helal turizm yaklaşımının, turizm faaliyetleri içerisinde oldukça geç yer almaya başladığı görülmektedir. Bunun birçok nedeni olmasına karşın en önemlisi sanayi devriminin batılı devletlerde ortaya çıkmış olmasıdır (Pamukçu, 2017; Saraç, vd., 2019, s. 7).

Sanayi devrimiyle bireylerin eğitim seviyesi ve dolayısıyla ekonomik gelirlerinde artış olmuştur. Yaşanan teknolojik gelişmeler bireylerin daha fazla boş zamanı olmasını sağlamış ve insanlar kısa sürede daha çok seyahat etme firsatı yakalamışlardır (Kozak, Kozak, Kozak, 2014, s. 31). Bu doğrultuda artı̧̧ gösteren seyahat faaliyetleri sonucunda turizm gelişmiş; batılı devletlerin din, düşünce, inanç ve yaşayış biçimleri doğrultusunda bir çehre kazanmıştır. İslam dinine mensup helala duyarlı bireyler ise bu nedenle uzun bir süre bu faaliyetlerde bulunamamıştır (Saraç, vd., 2019, s. 7).

İslam dini çevreyi korumayı emreden, israfı yasaklayan, insan sağlığına zararlı yiyecekleri haram kılan ve toplum inancına hoşgörülü olan bir düstura sahiptir (Kaya ve Batman, 2017). Bu durum İslamiyet'in toplumsal hayata faydali, çevreyi tahrip etmeyen bir sürdürülebilir turizm gelişimini desteklediği anlaşılmaktadır (Batman, 2017, s. 32). Diğer yandan İslam dinine mensup helala duyarlı turistlerin geldikleri yere geri döneceklerine yönelik inançları turizm faaliyetlerine olabildiğince benzerlik göstermektedir. İslamiyet seyahat etmeyi emretmektedir. Hz. Muhammed (sav) bir hadisinde "seyahat eden sihhat bulur" buyurmuşlardır (bk. Ahmet b. Hanbel, 3/280; Aclunî, 1/445). Öte yandan Allah'ın yarattığı kâinatı bir 
anlam yükleyerek gezmek görmek de sevap kazanmaktır (Aydın, 1966, s. 201; Batman ve Arpac1, 2016; Pamukçu, 2017, s. 26).

Literatüre bir bütün olarak bakıldığında İslam dini esaslarıyla çatışmayan seyahat ve tatil esnasında dini vecibelerini yerine getirebilmeye imkân tanıyan etkinliklerin ve turizm faaliyetlerinin helal dairede teşvik edildiği görülmüştür. Bu bağlamda helal turizm yaklaşımının sürdürülebilir turizm çeşidi olarak ele alınıp geliştirilmesi; çevrenin korunmasında, israfin önüne geçilmesinde, sosyal yaşantıya ve dini inançlara değer verilmesinde oldukça önemlidir (Saraç, vd., 2019, s. 8).

Araştırmanın literatürdeki yerini belirlemek amacıyla yapılan alanyazın taramasına göre Assante vd. (2012) çalışmalarında Hawaii'deki Oahu adasındaki, Dağlı (2018) çalısmasında Düzce Akçakoca'daki, Koçoğlu, vd., (2020) ise Karabük Safranbolu'daki yerel halkın sürdürülebilir turizmin gelişimine yönelik bakış açılarını öğrenmeye çalışıştır. Diğer yandan Alagöz vd. (2015), çalışmalarında otel işletmeleri ve seyahat acentelerinin sürdürülebilir turizmin gelişmesine yönelik tutumlarını ölçmeye çalışmıştır. Öte yandan Avcıkurt ve Güdü Demirbulat (2016), çalışmalarında turist rehberlerinin sürdürülebilir turizm gelişimine yönelik bakış açılarını ortaya koymaya çalışmıştır. Bu araştırmada ise Müslüman dostu otellerde konaklayan İslam dinine mensup mütedeyyin turistlerin sürdürülebilir turizm gelişimine yönelik tutumları ölçülmeye çalışılmıştır. Araştırma bu yönüyle literatürdeki boşluğu tamamlamakta ve arz belirleyicilerine farkındalık oluşturması bakımından önem taşımaktadır.

\section{Yöntem}

Araştırmada nicel yaklaşım benimsenmiş olup, veriler anket tekniği ile toplanmıştır. Araştırmada kullanılan anket formu Ayazlar'nn (2016) Sus-Tas ölçeğinden yararlanılarak oluşturulmuştur. Ankette 5'li Likert tipi ölçek kullanılmıştır.

Araştırmada uygulama alanı olarak Afyon merkez ilçede yer alan 5 yıldızlı helal konseptli oteller tercih edilmiştir. Bu doğrultuda araştırmanın ana kütlesini Afyon merkezdeki helal konseptli otellerde konaklayan turistler oluşturmaktadır. Araştırmanın Afyon'da yapılmasının en önemli nedeni, Afyon merkezin helala duyarlı turistlerin tatil yapabilmesi için önemli bir destinasyon olması ve Afyon merkezde kümelenmiş 5 yıldızlı helal konseptli otellerin yer almasıdır.

Veriler 10.07.2019-10.10.2019 tarihleri arasında toplanmıştır. Tüm ana kütleye ulaşmak mümkün olmadı̆̆ından örnekleme yoluna gidilmiş ve kolayda örnekleme yöntemi tercih edilmiştir. Örneklem büyüklüğünün belirlenmesinde Sekaran'ın (1992) araştırma evrenindeki bireylerinin sayısının bir milyon ve üzeri olması durumunda 0.95 güvenilirlikle 384 örneklem büyüklüğünün yeterli olacağ1 görüşü dikkate alınmış ve 523 helala duyarlı turiste anket uygulanmıştır. Buna karşın 37 anket eksik ve yanlış doldurulduğundan analizlere dâhil edilmemiş; araştırma 486 örneklem üzerinden gerçekleştirilmiştir. Verilen analizinde temel betimleyici analizler, açıklayıcı faktör analizi ve Pearson korelasyon analizleri kullanılmışır.

Helala duyarlı turistlerin sürdürülebilir turizm gelişimi algılarının tespit edilmesine yönelik geliştirilen hipotezler;

H1: Toplum merkezli turizm boyutu, sürdürülebilir turizm gelişimini oluşturan diğer tüm boyutlarla pozitif ilişkilidir.

H2: Ekonomik fayda boyutu, çevresel sürdürülebilirlik, sürdürülebilir planlama ve ziyaretçi memnuniyeti boyutlarıla pozitif ilisskilidir.

H3: Çevresel sürdürülebilirlik boyutu, sürdürülebilir planlama ve ziyaretçi memnuniyeti boyutlarıyla pozitif ilişkilidir.

H4: Sürdürülebilir planlama boyutu, ziyaretçi memnuniyeti boyutuyla pozitif ilişkilidir.

\section{Bulgular}

\section{Demografik Bulgular}

Tablo 1'de örneklemin demografik özelliklerine yönelik bulgular yer almaktadır. Buna göre örneklemin $\% 50,1$ 'i kadın, \%49,9’u ise erkektir. Örneklemin çoğunluğunun \%68,9 oranla evli olduğu görülmektedir. Yaş aralığına bakıldığında örneklemin en yoğun olduğu yaş grubunun \%33,7 oranla 30-41 yaş arası olduğu tespit edilmiştir. Örneklemin çoğunluğu ise \%33 oranla lisans mezunlarından oluşmaktadır. 
Tablo 1. Katılimclarn Demografik Özellikleri

\begin{tabular}{|c|c|c|c|c|c|}
\hline Cinsiyet & Frekans & Yüzde & Medeni durum & Frekans & Yüzde \\
\hline Kadın & 241 & 50,1 & Evli & 326 & 68,9 \\
\hline Erkek & 240 & 49,9 & Bekâr & 147 & 31,1 \\
\hline Toplam & 481 & 100,0 & Toplam & 473 & 100,0 \\
\hline Yaş & Frekans & Yüzde & Eğitim durumu & Frekans & Yüzde \\
\hline $18-29$ yaş & 113 & 23,6 & İlköğretim & 34 & 7,1 \\
\hline 30-41 yaş & 161 & 33,7 & Ortaöğretim & 100 & 21,0 \\
\hline $42-53$ yaş & 115 & 24,1 & Ön lisans & 148 & 31,1 \\
\hline 54-65 yaş & 74 & 15,5 & Lisans & 157 & 33,0 \\
\hline 66 yaş ve üstü & 15 & 3,1 & Lisansüstü & 37 & 7,8 \\
\hline Toplam & 478 & 100,0 & Toplam & 476 & 100,0 \\
\hline
\end{tabular}

\section{Helala Duyarlı Turistlerin Sürdürülebilir Turizm Gelişimine Yönelik Açıklayıcı Faktör Analizi}

Araştırmada sürdürülebilir turizm gelişimine yönelik ölçeğin boyutsal yapılarını tespit etmek, geçerlilik ve güvenilirliklerini belirlemek amacıyla açılayıcı faktör analizine başvurulmuştur. Tablo 2'de sürdürülebilir turizm gelişimine yönelik açlklayıcı faktör analizi sonuçları yer almaktadır.

Tablo 2. Sürdürülebilir Turiẓm Gelişimine Yönelik Açıklaynı Faktör Analiẓi Tablosu

\begin{tabular}{|c|c|c|c|c|}
\hline & $\begin{array}{c}\text { Sürdürülebilir Turizm Gelişimine Yönelik } \\
\text { Ifadeler }\end{array}$ & $\begin{array}{l}\text { Faktör } \\
\text { Yükleri }\end{array}$ & Varyans \% & $\begin{array}{l}\text { Güvenirli } \\
k \text { Analizi }\end{array}$ \\
\hline \multirow{4}{*}{ Ekonomik Fayda } & A1 &, 861 & 35,31 &, 868 \\
\hline & A2 & ,799 & & \\
\hline & A3 & ,779 & & \\
\hline & A4 & ,640 & & \\
\hline \multirow{6}{*}{$\begin{array}{l}\text { Toplum Merkezli } \\
\text { Turizm }\end{array}$} & B1 & ,935 & 17,12 &, 826 \\
\hline & B2 & 894 & & \\
\hline & B3 & 844 & & \\
\hline & B4 & ,736 & & \\
\hline & B5 & ,650 & & \\
\hline & B6 & ,426 & & \\
\hline \multirow{5}{*}{$\begin{array}{l}\text { Çevresel } \\
\text { Sürdürülebilirlik }\end{array}$} & C1 & ,859 & 6,04 & ,907 \\
\hline & $\mathrm{C} 2$ & 829 & & \\
\hline & C3 & ,798 & & \\
\hline & $\mathrm{C} 4$ & ,640 & & \\
\hline & C5 & ,589 & & \\
\hline \multirow{3}{*}{$\begin{array}{l}\text { Sürdürülebilir } \\
\text { Planlama }\end{array}$} & D1 & 807 & 3,39 &, 844 \\
\hline & D2 & ,784 & & \\
\hline & D3 & ,628 & & \\
\hline \multirow{3}{*}{$\begin{array}{l}\text { Ziyaretçi } \\
\text { Memnuniyeti }\end{array}$} & E1 &, 511 & 2,05 & ,760 \\
\hline & E2 & ,506 & & \\
\hline & E3 &, 417 & & \\
\hline
\end{tabular}

Güvenilirlik Analizi: 0,849; Çıkarım Yöntemi: Temel Bileșenler Analizi; Döndürme Yöntemi: Direct Oblimin, İterasyon Sayısı: 8, Varyans toplamı: 63,92; KMO Uygunluk Ölçütü: 0,912; Bartlett Küresellik Testi x2: 6075,045 p: 0,000

$\mathrm{Bu}$ analize göre öncelikle ölçeğe güvenilirlik analizi yapılmış ve içsel tutarlılık (cronbach alpha) kat sayısı tespit edilmiştir. Ölçeğin güvenilir ve geçerli kabul edilebilmesi için bu değerin 0,70 'in üzerinde olması beklenmektedir (Nunnaly ve Bernstein, 1994). Bu doğrultuda güvenirlik analizi “,849” değeri ile ölçeğin geçerli ve güvenilir olduğunu ortaya koymaktadır.

Sonrasında açıklayıcı faktör analizleri uygulanmıştır. Bu kapsamında Temel Bileşenler Analizi ve Direct Oblimin rotasyon tekniği kullanılmıştır. Bartlett Küresellik testinin anlamlı olması ve Kaiser-MeyerOlkin değerinin 0,912 olması örneklem büyüklüğunün faktör analizi için yeterli olduğunu göstermektedir (Büyüköztürk, 2010). Araştırmanın toplam varyansına bakıldığında 63,92 olduğu görülmektedir. Scherer vd., (1988)'e göre bu oranın \%50'den yüksek olması gerekmektedir. Bu doğrultuda analizin geçerli olduğu sonucuna ulaşılmaktadır.

Araştırmanın faktör analizinde, sürdürülebilir turizm gelişimine yönelik iki ifadenin binișik olduğu tespit edilmiş ve bu ifadeler analizden çıkarılmıştır. Bu bağlamda ölçeğe ait beş boyut belirlenmiştir. $\mathrm{Bu}$ boyutlar; ekonomik fayda, toplum merkezli turizm, çevresel sürdürülebilirlik, sürdürülebilir planlama ve ziyaretçi memnuniyetidir. Tablo 2'de yer alan bilgiler incelendiğinde, birinci faktör (4 madde) ekonomik 
fayda, ikinci faktör (6 madde) toplum merkezli turizm, üçüncü faktör (5 madde) çevresel sürdürülebilirlik, dördüncü faktör (3 madde) sürdürülebilir planlama, beşinci faktör (3 madde) ziyaretçi memnuniyeti olarak adlandırılmıştır.

Tablo 3’te katılımcıların sürdürülebilir turizm gelişimine ilişkin tutumlarının ortalamaları yer almaktadır.

Tablo 3. Sürdürülebilir Turizm Gelişimine Yönelik. Boyutlarn Ortalamalar

\begin{tabular}{lcc}
\hline Boyutlar & Ortalama & S. Sapma \\
\hline Çevresel Sürdürülebilirlik & 4,69 &, 71275 \\
Sürdürülebilir Planlama & 4,55 &, 66768 \\
Ekonomik Fayda & 4,46 &, 74638 \\
Ziyaretçi Memnuniyeti & 4,44 &, 66465 \\
Toplum Merkezli Turizm & 3,44 & 1,23218 \\
Sürdürülebilir Turizm Gelişimi Genel Algisı Boyutu & \multicolumn{2}{c}{ Ortalamanın Ortalamasi } \\
\hline
\end{tabular}

En yüksek ortalamaya ait boyutun "çevresel sürdürülebilirlik" (4,69) olduğu, bunu sırasıyla "sürdürülebilir planlama" $(4,55)$, "ekonomik fayda" $(4,46)$ ve "ziyaretçi memnuniyeti" boyutlarının izlediği görülmektedir. Katılımcıların en düşük tutuma sahip boyutun "toplum merkezli turizm" $(3,44)$ olduğu görülmektedir. Öte yandan ölçeğe ait tüm ifadelerin ortalamasının alındığı sürdürülebilir turizm gelişimi genel ortalaması 4,2283 düzeyinde çok yüksek (1,00-1,79: çok düşük, 1,80-2,59: düşük, 2,60-3,39: orta, 3,40-4,19: yüksek, 4,20-5,00: çok yüksek) bir algiya sahiptir (Özdamar, 2003, s. 32). Bu sonuçlara göre, katılımcıların sürdürülebilir turizm gelişimine yönelik boyutlar üzerinde oldukça olumlu bir algiya sahip oldukları görülmektedir.

\section{Sürdürülebilir Turizm Gelişimine Yönelik Boyutlar Arasındaki İlişki}

Sürdürülebilir turizm gelişim ölçeğine ait boyutların birbirleriyle ilişkilerini tespit etmek üzere pearson korelasyon analizi gerçekleştirilmiştir. Bu analizin sonuçlarına Tablo 4'te yer verilmiştir. Boyutlar arasında ilişskinin değerlendirilmesinde $n>100$ olmak üzere aşağıda gösterilen aralıklar referans alınmıştır (Sökmen, 2000);

Tablo 4. Sürdürülebilir Turiżm Gelisimine Yönelik Boyutlar Arasndaki Korelasyon Analizi

\begin{tabular}{lccccc}
\hline Faktörler & $\boldsymbol{E F}$ & $\boldsymbol{T M T}$ & $\boldsymbol{C S}$ & $\boldsymbol{S P}$ & $\boldsymbol{Z M}$ \\
\hline Ekonomik Fayda & 1 & & & & \\
Toplum Merkezli Turizm &, 074 & 1 & & & \\
Çevresel Sürdürülebilirlik &, $536^{* *}$ &, 044 & 1 & & \\
Sürdürülebilir Planlama, &, $585^{* *}$ &, $121^{* *}$ &, $532^{* *}$ & 1 & \\
Ziyaretçi Memnuniyeti &, $653^{* *}$ &, $265^{* *}$ &, $488^{* *}$ &, $548^{* *}$ & 1 \\
\hline
\end{tabular}

${ }^{* *} \mathrm{p}<0.01$ ”, $\mathrm{r}=0,71-1,00$ : güçlü, $\mathrm{r}=0,41-0,70$ : orta, $\mathrm{r}=0,21-0,40$, zaylf, $\mathrm{r}=0,00-0,20$ : çok zayıf (Özdamar, 2003; Terzi, 2018).

Tablo 4'e göre tüm değişkenler birbirleriyle ilişki içerisindedir. Hipotezlerin kabul-ret durumunu ortaya koymak üzere analiz sonuçları değerlendirildiğinde; toplum merkezli turizm boyutunun ekonomik fayda $(r=, 074)$, çevresel sürdürülebilirlik $(r=, 044)$ ve sürdürülebilir planlama $(r=, 121)$ ile çok zayıf derecede pozitif ilişki içerisinde olduğu görülmektedir. Ziyaretçi memnuniyeti boyutu $(r=, 265)$ ile de zayıf derecede pozitif ilişkili olduğu tespit edilmiştir. Toplum merkezli turizm boyutu ile en fazla pozitif ilişkili olan boyutun ziyaretçi memnuniyeti olduğu görülmektedir. Bu sonuca göre H1: (Toplum merkezli turizm boyutu, sürdürülebilir turizm gelişimini oluşturan diğer tüm boyutlarla pozitif ilişkilidir.) hipotezi kabul edilmiştir.

Ekonomik fayda boyutunun; toplum merkezli turizm boyutu $(\mathrm{r}=, 074)$ ile çok zayıf derecede pozitif; çevresel sürdürülebilirlik $(\mathrm{r}=, 536)$, sürdürülebilir planlama $(\mathrm{r}=, 585)$ ve ziyaretçi memnuniyeti $(\mathrm{r}=, 653)$ boyutlarıyla orta derecede pozitif ilişkili olduğu belirlenmiştir. Ekonomik fayda ile en fazla pozitif ilişskili olan boyutun ise yine ziyaretçi memnuniyeti olduğu görülmektedir. Bu sonuca göre H2: (Ekonomik fayda boyutu, çevresel sürdürülebilirlik, sürdürülebilir planlama ve ziyaretçi memnuniyeti boyutlarryla pozitif ilişkilidir.) hipotezi kabul edilmiştir. 
Çevresel sürdürülebilirlik boyutunun ise ziyaretçi memnuniyeti boyutu $(r=, 488)$ ile zayıf; sürdürülebilir planlama boyutu $(r=, 532)$ ile orta derecede pozitif ilişkili olduğu görülmektedir. Bu sonuca göre H3: (Çevresel sürdürülebilirlik boyutu, sürdürülebilir planlama ve ziyaretçi memnuniyeti boyutlarıyla pozitif ilişkilidir.) hipotezi kabul edilmiştir.

Sürdürülebilir planlama boyutu ile ziyaretçi memnuniyeti boyutu arasında $(r=, 548)$ ise orta derecede pozitif ilişkili bulunmaktadır. Bu sonuca göre H4: (Sürdürülebilir planlama boyutu, ziyaretçi memnuniyeti boyutuyla pozitif ilişkilidir.) hipotezi kabul edilmiştir.

\section{Tartışma, Sonuç ve Öneriler}

Helala duyarlı turistlerin sürdürülebilir turizm gelişimine yönelik algiların tespit edilmeye çalışıldığı bu araştırmada yapılan faktör analizine göre; ekonomik fayda, toplum merkezli turizm, çevresel sürdürülebilirlik, sürdürülebilir planlama ve ziyaretçi memnuniyeti olmak üzere beş boyuta ulaşılmıştır.

Alanyazına bakıldığında Biçici (2003), Alagöz vd. (2015), Dağlı (2018) ve Koçoğlu vd. (2020), sürdürülebilir turizmin gelişimine yönelik yerel halkın ve diğer turizm paydaşlarının tutumlarının ölçüldüğü çalışmalarında ulaştıkları altı farklı boyut ile bu araştırmadan farklılaşmaktadır. Bunun nedeni; bu araştırmada turizmin sosyal çevre üzerindeki baskının ortadan kaldırılması gerektiğini destekleyen "sosyal maliyet" boyutu ile turizmin yöre halkın istihdamına ve üretimi gibi unsurlara fayda sağlaması gerektiğini savunan "yerel halka yönelik fayda" boyutunun tek faktör altında toplanmış olmasıdır. Öte yandan Avcıkurt ve Güdü Demirbulat'ın (2016), turist rehberlerinin sürdürülebilir turizmin gelişmesine yönelik tutumlarını ölçmeye çalıştıkları araştırmada ise yedi faktöre ulaşılmışır. Bu araştırmanın yedi boyut altında toplanmasının nedeni "toplum merkezli ekonomi” adlı yeni bir boyutun ortaya çıkmasıdır.

$\mathrm{Bu}$ araştırmada faktör analizi sonucunda ortaya çıan boyutların ortalamalarına göre önem sırası; çevresel sürdürülebilirlik, sürdürülebilir planlama, ekonomik fayda, ziyaretçi memnuniyeti ve toplum merkezli turizmdir. Bu doğrultuda Koçoğlu vd. (2020) çalışmasıyla benzerlik göstermektedir. Öte yandan Assante vd. (2012), çalışmalarında ekonomik fayda boyutu yüksek bir alg1 ortalamasına sahiptir. Bu yönüyle bu araştırmaya benzerlik gösterse de çevresel sürdürülebilirlik algısının düşük bir ortalamaya sahip olmasıyla bu araştırmadan farklılaşmaktadır.

Tüm bu sonuçlara bağlı olarak, sürdürülebilir turizmde önemli bir unsur olan ziyaretçi memnuniyeti boyutunda yapılan olumlu faaliyetler, sürdürülebilir turizm gelişimine yönelik diğer boyutlar üzerinde olumlu değişimler oluşturacaktır. Bununla birlikte sürdürülebilir turizm ile toplum merkezli turizm, çevresel sürdürülebilirlik, sürdürülebilir planlama ve ziyaretçi memnuniyeti boyutlarında ortaya çıan olumlu bir durumun, ekonomik fayda boyutunda bir iyileşme sağlayacağı düşünülmektedir.

$\mathrm{Bu}$ araștırmada yapılan pearson korelasyon analizlerinde toplum merkezli turizm boyutu, sürdürülebilir turizm gelişiminin diğer boyutlarıyla pozitif; ancak çok zayıf düzeyde ilişkilidir. Buna karşın bu boyutun ziyaretçi memnuniyeti ile orta düzeyde pozitif bir ilişki içerisinde olduğu görülmektedir. $\mathrm{Bu}$ durum toplum merkezli turizm alg1ları yüksek olan İslam dinine mensup mütedeyyin turistlerin, turizmde ziyaretçi memnuniyetinin sağlanması gerektiğine dair algılarını da arttırmaktadır. Diğer yandan ekonomik fayda boyutu, toplum merkezli turizm boyutu dışında diğer tüm boyutlarla orta düzeyde bir ilişki içerisindedir. Buna karşın belala duyarl turistlerin ekonomik fayda boyutu algıları arttıkça en çok ziyaretçi memnuniyetinin karşılanması gerektiğine dair algilar artmaktadır. Öte yandan mütedeyyin turistlerin çevresel sürdürülebilirlik boyutu algıları arttıkça sürdürülebilir planlama algıları; sürdürülebilir planlama algıları arttıkça ziyaretçi memnuniyetinin karşılanması gerektiğine dair algıları da artmaktadır.

Helala duyarlı turistlerin sürdürülebilir turizm gelişimi algıları 4,22 ile çok yüksek bir ortalamaya sahiptir. $\mathrm{Bu}$ bulgu 1şığında helala duyarlı turistlerin turizm faaliyeti gösterdikleri destinasyonun sürdürülebilirliğine duyarlı oldukları sonucuna ulaşılmaktadır. Bunun yanı sıra en yüksek ortalamaya sahip sürdürülebilir turizm gelişimi boyutu çevresel sürdürülebilirliktir $(4,69)$. Bu bulgu onların İslam dinin gerekleri arasında sayılan çevrenin korunması ve israftan kaçllması emirlerini benimsedikleri ve o doğrultuda yaşadıklarına işaret etmektedir. Bu nedenle mütedeyyin turistlerin gerçekleştirdikleri turizm faaliyetlerinin sürdürülebilirliğe katkı sağlayan bir yapısı olduğu bu nedenle de bu turizm yaklaşımını geliştirilmesi önerilebilmektedir.

Helala duyarlı turistler, öncelikle çevresel konulara dikkat edilmesi gerektiğini düşünmektedir. Diğer yandan en yüksek ikinci ortalamanın da sürdürülebilir planlama boyutunda gerçekleştiği göz önünde 
bulundurulduğunda helala duyarlı turistlerin sürdürülebilir turizm gelişiminde uzun vadeli planlamaların yapılması gerektiğini savundukları tespit edilmiştir. Öte yandan ekonomik faydanın başta ziyaretçi memnuniyeti olmak üzere turizmin yerel halka ve bireyler katkı sağlayacağını düşünmektedirler

Bundan sonra yapılacak çalışmalarda araştırmacılara; farklı turizm destinasyonlarındaki helala duyarlı turistlerin tutumlarının araştırlması önerilebilir. Bunun yanı sıra helal konseptli olmayan kitlesel turizmin gerçekleştirildiği destinasyonlarda turizm faaliyetlerini sürdüren turistlerin sürdürülebilir turizme bakış açıları tespit edilerek benzerlik ve farklılıkları karşılaştırılabilir.

\section{Etik Beyan}

"Helala Duyarl Turistlerde Sürdürülebilir Turiz̧m Gelişmesine Yönelike. Alg̨ Araştırması" başlıklı çalışmanın yazım sürecinde bilimsel, etik ve alınt1 kurallarına uyulmuş; toplanan veriler üzerinde herhangi bir tahrifat yapılmamış ve bu çalışma herhangi başka bir akademik yayın ortamına değerlendirme için gönderilmemiştir.

\section{Kaynakça}

Abdollahzadeh, G. ve Sharifzadeh, A. (2014). Rural residents' perceptions toward tourism development: A study from Iran. International Journal of Tourism Research, 16 (2), 126-136.

Alagöz, G., Güneş, E. ve Uslu, A. (2015). Otel işletmeleri ve seyahat acentaları yöneticilerinin sürdürülebilir turizme bakış açısı: Bir alan araştırması. Gümüshane Üniversittesi Sosyal Bilimler Elektronik Dergisi, 6 (14), 83-98.

Arpacı, Ö. ve Batman, O. (2015). Helal konseptli otel işletmelerinin yüksek ve düşük sezonda algılanan hizmet kalitesinin müssteri sadakati ve müşteri değeri üzerine etkisi helal turizm. Seyahat ve Otel İsletmeciliğgi Dergisi, 12(3), 73-86.

Arslan Ayazlar, R. (2016). Sürdürülebilir turizm tutum (SUS-TAS) ölçeğinin geçerlilik ve güvenilirlik çalışması: Didim yerel halk örneği. II. Ulusal Sürdürülebilir Turizm Kongresi. Antalya, 28-30 Nisan.

Assante, L. M., Wen, H. I. ve Lottig, K. J. (2012). Conceptualization of modeling resident attitudes on the environmental impacts of tourism: A case study of Oahu, Hawaii. Tourism Planning and Development, 9 (2), 101118.

Avcıkurt, C. ve Güdü Demirbulat, Ö. (2016). Turist rehberlerinin sürdürülebilir turizme bakış açısı. Journal of Tourism Theory and Research, 2 (2), 173-191.

Aydın, A. A. (1966). İslam'nn seyahate verdiği önem. Diyanet İ̧leri Başkkanluğ Dini Ablaki- Edebi- Mesleki Aylhk Dergisi, 5.(8), 201-203.

Batman, O. (2017). Sorularla helal turizm / helal turizm nedir veya ne değildir?, I. International Halal Tourism Congress. Antalya, 07-09 Nisan.

Batman, O. ve Arpac1, Ö. (2016). Helal turizmin felsefi teorisi uygulaması. OmniScriptum GmbH Co. KG: Türkiye Alim Kitapları.

Büyükşalvarcı, A., Şapçılar, M. C. ve Adabalı, M. M. (2016). Konya mentioned as the tourism capital of islamic world and effects of Konya's tourism. Journal of International Social Research, 9(45), 1054-1064.

Collin, P. H. (2004). Dictionary of environment and ecology. London: Bloomsbury Publishing Plc.

Çakılcıŏlu, M. (2013). Turizm odaklı sürdürülebilir kalkınma için bir yöntem önerisi. Tasarm +Kuram Dergisi, 9 (16), $27-42$.

Dağlı, Z. (2018). Sürdürülebilir turizmin gelişimine yönelik yerel halkın tutumlarını incelemeye ilişkin bir araştırma: Akçakoca destinasyonu. Seyahat ve Otel İsletmecilig̈i Dergisi, 15 (3), 603-619.

Deng, J., King, B. \& Bauer, T. (2002). Evaluating natural attractions for tourism. Annals of Tourism Research, 29(2), $422-438$.

Dolnicar, S., Crouch, G. I., \& Long, P. (2008). Environment-friendly tourists: What do we really know about them?. Journal of Sustainable Tourism, 16(2), 197-210.

Kahraman, N. ve Türkay, O. (2014). Turiżm ve çevre, Ankara: Detay Yayıncillk.

Kaya, M.C. ve Batman, O. (2017). Helal turizm yaklaşımı sürdürülebilir turizmin araçlarından biri olabilir mi? I. International Halal Tourism Congress. Antalya, 07-09 Nisan.

Kim, K., Uysal, M. ve Sirgy, M. J. (2013). How does tourism in a community impact the quality of life of community residents?. Tourism Management, (36), 527-540.

Koçoğlu, C. M., Saraç, Ö. ve Batman, O. (2020). Safranbolu'da sürdürülebilir turizm gelişmesine yönelik yerel halkın tutumlar1, Türk Turizm Araşttrmalar Dergisi, 4(1): 202-219.

Kozak, M., ve Martin, D. (2012). Tourism life cycle and sustainability analysis: Profit-focused strategies for mature destinations. Tourism Management, 33(1), 188-194.

Kozak, N., Kozak, M.A. ve Kozak, M. (2014). Genel turizm ilkeler kavramlar, (16. Baskı), Ankara: Detay Yayıncilık.

Lim, C. ve McAleer, M. (2005). Ecologically sustainable tourism management. Environmental Modelling and Software, 20(11), 1431- 143.

Nunnally, J. C. ve Bernstein, I. H. (1994). Psychometric theory (3rd ed.), New York: McGraw-Hill.

Özdamar, Ö. (2003). Modern bilimsel arasttrma yöntemleri, Eskişehir: Kaan Kitabevi. 
Pamukçu, H. (2017). Konaklama işletmelerinde helâl turiz̨m standardizasyonu önerisi (Doktora Tezi). Sakarya Üniversitesi, Sosyal Bilimler Enstitüsü, Sakarya.

Pamukcu, H., ve Sarıssık, M. (2020). Suggestions for standardization of halal tourism in hospitality industry. Journal of Islamic Marketing.

Sarac, O., Batman, O. \& Kiper, V. O. (2019). Comparing hedonism with responsible tourism diversities. Journal of Tourismology, 5(2), 151-170.

Saraç, Ö. ve Tanrısever, C. (2018). Kastamonu'da yeniden işlevlendirilen tarihi yapıların sürdürülebilirliğe etki eden çekicilik faktörleri. Anatolia: Turizm Araștırmalar Dergisi, 29(2), 151-163.

Sarı, Y. (2017). Bir alternatif turizm çeşidi olarak "tefekkür turizmi” üzerine kavramsal bir çalışma. I. International Halal Tourism Congress. Antalya, 07-09 Nisan.

Scherer, R. Wiebe, F. A., Luther, D. C. ve Adams,J. S. (1988). Dimensionality of coping: Factorstability using the ways of coping questionnaire, Psychological Report, (62), 763-770.

Sekaran, U. (1992). Research methods for business, a skill building approach, USA: John Wiley \& Sons Inc.

Swarbrooke, J. (1999). Sustainable tourism management (2nd Edition). London: CABI Publishing.

Şen, S. D. (2010). Turizmin çevresel etkileri ve bir çözüm olarak ekoturizm (Yüksek Lisans Tezi). Mersin Üniversitesi, Sosyal Bilimler Enstitisü, Mersin.

Terzi, Y. (2018). Temel İstatistik Notlar II, Ondokuz Mayıs Üniversitesi, Fen-Edebiyat Fakültesi, İstatistik Bölümü.

Tekin, Ö. A. (2014). İslami turizm: Dünyadaki ve Türkiye'deki genel durum üzerine bir inceleme. Uluslararası Sosyal Arastirmalar Dergisi, 7(29), 750-766.

Tekin, Ö. A. (2016). İslami turizm konseptinde hizmet veren konaklama işletmeleri üzerine bir inceleme. Uluslararası Sosyal Araștirmalar Dergisi, 9(42), 2046-2058.

Tekin, Ö. A. ve Yılmaz, E. (2016). İslami turizm konseptinde hizmet veren konaklama işletmeleri üzerine bir inceleme. Uluslararası Sosyal Araştırmalar Dergisi, 9(42), 2046-2058.

Türkay, O. ve Saraç, Ö. (2019). Altyapı, üstyap1 ve çevre sorunlarının turist şikayetleri kapsamında değerlendirilmesi ve yerel yönetimlerin çözüm potansiyeli: Antalya örneği. Gümüshane Üniversitesi Sosyal Bilimler Enstitüsü Elektronik Dergisi, 10(Ek Say1), 98-110

Weaver, D. ve Oppermann, M. (2000). Tourism management. Australia: John Wiley Sons

Yeşiltaş, M., Cankül, D. ve Temizkan, R. (2012). The effects of religious life style on hotel selection. Electronic Journal of Social Sciences, 39, 193-217.

\section{EXTENDED ABSTRACT}

Tourism is a very old travel activity. These activities were carried out for religion, health and trade early on. Differences in business life after the industrial revolution; has increased the needs of people such as vacation, rest and entertainment and these needs have been caused to be met with the sea-sun-sand trio.

The technological and economic developments encountered pave the way for tourism activities to be realized in masses. Excessive use without allowing the social structure or environment to renew itself, causes the natural beauty, cultural structure, ecological balance and biological diversity in these regions to be spoiled (Kahraman, \& Türkay, 2018). Avoiding this becomes possible by supporting the sustainable tourism development of destinations. In order to ensure sustainable tourism development, it is necessary for the natural, historical and socio-cultural values that constitute the tourism attractions to be protected and developed, and the quality of them must be increased in the way that they can reach to future generations (Saraç, \& Tanrısever, 2018). Within this context, in the sustainability of tourism; economic, social, cultural and environmental dimensions need to be evaluated together (Dolnicar, Crouch, \& Long, 2008). Because while tourism businesses or destinations exhibit activities aimed at obtaining economic income, they ignore the socio-cultural and environmental problems of their region. However, halal tourism approach is thought to have been important in ensuring sustainable tourism development recently. This tourism approach allows the tourists belonging to Islamic religion to carry out their religious duties and charges while taking part in their tourism activities. The biggest difference of this tourism approach from other sustainability-related approaches is that it is mostly carried out by tourists who have thoughts and beliefs belonging to Islam. In this respect, unlike mass tourism, halal tourism stands out with its structure that is ecological, prohibits waste and values human health and social life (Sar1, 2017, p. 507). The main purpose of this research is to determine the perceptions of halal-sensitive tourists towards sustainable tourism development. Determining the relationships between the dimensions related to sustainable tourism development is among the other aims of the study. Within this context, after a literature summary of sustainable tourism and halal tourism is presented, the findings obtained from the method and field research will be discussed. Quantitative approach has been adopted in the research and the data has been collected with questionnaire technique. The questionnaire used in the research was 
created by utilizing the Sus-Tas scale of Ayazlar (2016). A 5-point Likert scale was used in the survey. In the research, five-star halal concept hotels in the central district of Afyon were preferred as the application area. The most important reason for the research to be conducted in Afyon is that the center of Afyon is an important destination for halal-sensitive tourists to have a vacation and that there are five-star halal concept hotels clustered in the center of Afyon. The data were collected between the dates "10.07.201910.10.2019". Since it is not possible to reach the entire main mass, sampling method was used and convenience sampling method was preferred. In the determination of the sample size, if the number of individuals in the research universe of Sekaran (1992) is one million or more, the opinion of 384 sample size with 0.95 reliability is considered to be enough and a questionnaire was applied to 523 halal sensitive tourists. However, 37 questionnaires were not included in the analysis since they were missing and wrongly filled; the research was carried out on 486 samples. In the analysis of the data, basic descriptive analyzes, exploratory factor analysis and Pearson correlation analysis were used. The majority of the sample is seen to be married with a rate of $68.9 \%$. Considering the age range, it was determined that the age group with the highest concentration was between $30-41$ years old with a rate of $33.7 \%$. The majority of the sample consists of graduates with a rate of $33 \%$. It is seen that the highest average dimension in participants' attitudes towards sustainable tourism development is "environmental sustainability" (4.69), and it is followed respectively by "sustainable planning" (4.55), "economic benefit" (4.46) and "visitor satisfaction". It is seen that the lowest attitude of the participants is the "community centered tourism" (3.44). On the other hand, the overall average of sustainable tourism development, in which the expressions of the scale are averaged, has a very high perception with its rate '4.2283' (Özdamar, 2003, p. 32). According to these results, it is seen that the participants have a very positive perception on the dimensions of sustainable tourism development. When the analysis results are evaluated to reveal the acceptance-rejection status of the hypotheses; it seems that the community-centered tourism dimension has a very weak positive correlation with economic benefit $(r=, 074)$, environmental sustainability $(r=$, 044) and sustainable planning $(r=, 121)$. It was also found that it is positively-related at weak degree with the visitor satisfaction dimension $(r=, 265)$. It is seen that the most positively related dimension with the community-centered tourism dimension is visitor satisfaction. According to this result, H1: (Communitycentered tourism dimension is positively related to all other dimensions that constitute sustainable tourism development.) hypothesis was accepted. It has been determined that economic benefit dimension has very weak positive relationship with the community-centered tourism dimension $(r=074)$; and is moderately positively associated with environmental sustainability $(\mathrm{r}=, 536)$, sustainable planning $(\mathrm{r}=$, $585)$ and visitor satisfaction $(r=, 653)$. It is seen that the visitor satisfaction is again the dimension that is most positively associated with the economic benefit. According to this result, the hypothesis $\mathrm{H} 2$ : (Economic benefit dimension positively correlates with environmental sustainability, sustainable planning and visitor satisfaction dimensions) hypothesis was accepted. It is seen that the environmental sustainability dimension is weakly associated with the visitor satisfaction dimension $(\mathrm{r}=, 488)$; and is moderately positively associated with the sustainable planning dimension $(r=532)$. According to this result, H3: (Environmental sustainability dimension is positively associated with sustainable planning and visitor satisfaction dimensions) hypothesis was accepted. There is a moderately positive correlation between the sustainable planning dimension and the visitor satisfaction dimension $(\mathrm{r}=548)$. According to this result, H4: (Sustainable planning dimension is positively associated to visitor satisfaction dimension) hypothesis was accepted. In this research in which the perceptions of halal-sensitive tourists towards sustainable tourism development are tried to be determined, positive activities carried out in the dimension of visitor satisfaction which is an important factor in sustainable tourism, will create positive changes on other dimensions for sustainable tourism development. However, it is thought that a positive situation that emerges in terms of sustainable tourism and community-centered tourism, environmental sustainability, sustainable planning and visitor satisfaction will provide an improvement in the economic benefit dimension. In future studies, researchers may be suggested to investigate the attitudes of halalsensitive tourists in different tourism destinations. In addition, similarities and differences can be compared by determining the perspectives of the tourists who continue their tourism activities in the destinations where non-halal mass tourism is realized. 